\title{
Bulutangkis Service Exercise Model for Beginners
}

\author{
Benny Badaru ${ }^{1}$, Hasmyati ${ }^{2}$, Sufitriyono $^{3}$, Juhanis ${ }^{4}$, Hasbi Asyhari ${ }^{5}$ \\ Department of Physical Education, Health and Recreation, \\ Faculty of Sports Science, Makassar State University, Indonesia \\ 1'benny.b@unm.ac.id, ${ }^{2}$ hasmyati@unm.ac.id, ${ }^{3}$ sufitriyono@unm.ac.id, \\ 4juhanis@unm.ac.id, ${ }^{5}$ hasbiasyhari89@gmail.com
}

\begin{abstract}
The purpose of this research and development is to produce a badminton service training model for beginners. This research uses the research and development method of Research \& Development (R \& D) from Borg and Gall with 10 steps and produces an exercise model product. The subjects in this research and development were junior high school students consisting of 54 people. The model effectiveness test uses the badminton service test to determine the level of badminton service ability for junior high school age beginners. Initial test data carried out obtained student data of 23.64, then after being given treatment in the form of a badminton service training model, an increase in the students' badminton service ability was 34.12. So the badminton service training model developed is effective in increasing badminton service ability for junior high school age beginners. Based on the results of the development it can be concluded that: (1) The badminton service training model for beginners can be developed into 6 service training models consisting of 3 lob services and 3 short services (2) With the badminton service training model for beginners that has been developed, evidence of an increase The ability of this service stroke is shown in the results of testing the pre-test and post-test results, there is a significant difference between before and after the treatment model.
\end{abstract}

Keywords: Model, Service, Badminton and Beginners

\section{Introduction}

Badminton is a sport of achievement that is very well known throughout the world. Badminton is a sport that is played using the net, racket and ball with varying hitting techniques ranging from relatively slow to very fast accompanied by deceptive movements. In badminton, there are three types of service, namely short serve, high serve, and flick or half high serve[1]. However, usually serves are combined into the forehand and backhand types. Each type of service varies according to the playing situation on the field. In badminton game rules, service is the initial capital to be able to win the match.

Movement activity is often done by exercising at school. Sports are activities that are popular with students. One of them is badminton. Badminton is a sport that is popular and favored by the people of Indonesia, including the people of Makassar. It is proven that the majority in the community and schools have built badminton courts. In addition, various regions in Indonesia have held many badminton competitions between students, students and the public. The competition between students is an event or place for interest talent competition which is usually held in extracurricular schools.

In junior high school, physical education learning has an important role in student growth and development. Physical education learning as an educational tool can form perfect postures and body movements according to the functions of these body organs. This is shown by the 
shape of the body that is not slouched, does not tilt, can walk and jump well, and do other activities as it should without disturbing obstacles. Both aspects are developed by providing external stimulation. This will lead to activities in children in the form of learning as a channel for activities that have been owned by the previous child, namely in the form of training. Therefore, physical education learning that should be presented to children in the form of variations in the form of exercises and children's activities called learning while training. The use of infrastructure is one of the media to support students in better understanding the subject matter being taught [2]. The development of the Physical Education learning model is one of the efforts to help solve the problem of limited physical education facilities and infrastructure in schools. The development of physical education learning models carried out by Physical Education teachers can bring an innovative and creative learning atmosphere so that learning can be fun and motivate students to have more opportunities to exploit movement widely and freely according to their level of ability. The boring learning of junior high school students will cause decreased motivation to be involved in physical education learning [3]. This is reinforced by a statement [4] that one of the most appropriate motivations is from the trainer or teacher, motivation is needed for encouragement to do something caused by interest in a goal so that a response appears in the form of activity displays, so that students are interested in following the next process.

A player who cannot serve properly will be faulted. However, most coaches and players cannot pay special attention to properly train and master these basic techniques. The coach also rarely provides service training both long forehand serve and short backhand serve to his trainers. This is a big mistake, because service is crucial in getting a score. It is said that beginners are due to their ability to master badminton skills which are relatively new in participating in badminton sport coaching.

In the observations of the needs analysis carried out, it was found that students were less motivated in participating in badminton extracurricular training, especially in performing services because the training was boring and monotonous in nature. It can be seen from the training process that athletes do not immediately perform their duties to perform service movements but tend to directly play badminton. The results of teacher interviews with students at school also showed that most of the novice athletes who attended training at school were bored with the training model provided, especially in service training. So from the results of these observations, teachers and students at school need a new badminton service training model so that apart from being able to motivate students, it can also increase the quality of techniques in badminton.

The quality of service of students at school can also be seen from the results of tests conducted by researchers from simple randomized tests, it can be seen that there are still many athletes whose services are still involved at the net, the position of the racket and ball (shuttlecock) is not below the navel or waist, the direction of the ball at long serve, the ball does not reach the back of the badminton court, the direction of the ball does not fly high in a parabolic pattern.

Based on the above background, the researcher wants to develop a badminton service training model. For this reason, researchers will develop a badminton service training model for novice athletes at junior high school age in Makassar City. 


\section{Research Method}

The research was carried out at SMP Negeri 24 Makassar. The research subjects were junior high school students in Makassar City. Research implementation time according to borg and gall is 6 months. The instrument in this study used a service blow instrument in badminton. Development research includes experimental activities and improvements to a development product that can be used directly by users. This research method uses qualitative and quantitative approaches and uses the Research \& Development (R \& D) development model from [5] which consists of ten steps in the image below:

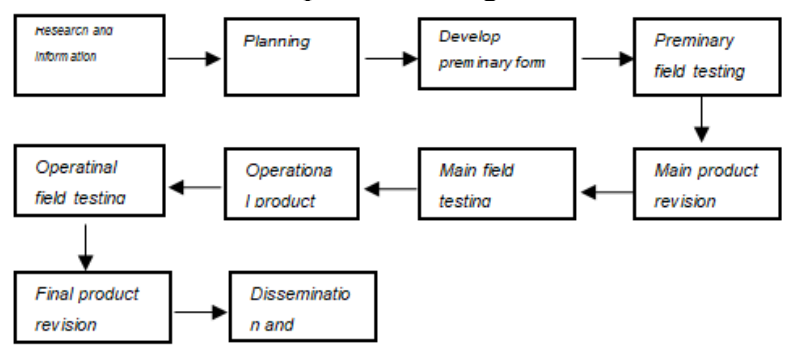

Source: Walter R. Borg and Meredith D. Gall, Educational Research: An Introduction, 4th Edition (New York: Longman Inc., 1983) [5]

Fig.1. Instructional Design R and D

Research and development or Research and Development (R\&D) is a process or steps to develop a new product or improve an existing product. While the development model used is the Research \& Development (R \& D) development model from [5]which consists of ten steps, among others: (1) The first time that is determined is the problem or potential that becomes the basis for developing the model; (2) Furthermore, information is collected as a rationale for drafting a concept; (3) Making a basic technique training model for Passingcontrolling (product design), the form of the design is a basic technique training model for Passing and controlling futsal at the age of junior high school; (4) Design validation, carried out by 3 experts, (5) Revision, from the results of expert testing (design validation); (6) Conduct small trials (with 10-12 subjects); (7) Revise the product (based on suggestions and small trial results); (8) Testing the use or testing of a larger group, 120 subjects; (9) Revision of the final product; and (10) Making reports on products in journals, work with publishers that can do commercial distribution. The same thing was also conveyed by [6]which states that research and development is a research method used to produce certain products, and to test the effectiveness of these products. Research and development is a process or steps to develop a new product or improve an existing product, which can be justified [7].

\subsection{Preliminary Research}

The first step in this research is to conduct a preliminary research by carrying out an analysis in the field. Needs analysis is carried out by observing the field, with sports that are newly developing in the community. This development model is expected to be a precise development that is very much needed in the development of basic service engineering training models for junior high school age beginners. 


\subsection{Model Development Planning}

The basic badminton technical training model was developed using Borg and Gall's development steps. At each stage of this research and development there are design steps outlined in the explanation. The next step is to create an initial product in the form of a series of model development which later can be used as a guide or guide to improve quality, skills and accuracy. The initial product is expressed in an exercise model. The development of training models is expected to be a product that can be developed systematically and logically, so that this product has effectiveness and efficiency that is suitable for use. In making products developed by researchers, researchers must consult badminton sports experts in order to produce the perfect product.

The models that plan to exercise short and long service techniques are:

a) Service Exercise Model I

b) Service Exercise Model II

c) Model of Service Exercise III

d) Model IV service exercise

e) Service Exercise Model V

f) Service Exercise Model VI

Data to find out the results of student assessments, an assessment rubric is needed. In this study, the steps taken for assessment were pretest and posttest in which prestest was to determine students' initial abilities and postest to determine the results after treatment. Suharti \& Darisman (2017) stated that in this study conducted observations twice, namely before (pretest) and after (posttest). After obtaining the results of the initial score and the final score then the scores are converted into values. Then the difference between the pretest and posttest values is calculated to get the gain value or the gain value [8]. The formula used in calculating the gain score is:

$$
g=\frac{\text { post test score }- \text { pretest score }}{\text { maximum possible score }- \text { pretest score }}
$$

\section{Results and Discussion}

\subsection{Model Development Results}

The results of the development of the model in this study, the researchers produced a product in the form of a script that presents various forms of training models for basic service techniques in badminton games for junior high school aged children. Based on the research method used by the researcher, one of the steps in the process of developing the model was data collection, in this case the researcher discussed with several badminton experts during training. This is used to find out how much it takes to develop a training model for basic technical techniques of service in badminton which will be developed by researchers and an initial draft of the basic badminton training model is made. The results of preliminary studies or findings in the field are then analyzed and discussed so that a result of the data that has been collected can be obtained. The formulation of these results is descriptive, with reference to the objectives of the preliminary research study. Researchers hope that the products produced later 
can improve the quality of learning the basic techniques of badminton service which can make students actively participate in learning, so that it is expected to improve their ability to play futsal. The resulting product is also expected to be able to assist Physical Education teachers in providing training on basic techniques of badminton service which are more varied by using the products produced. so it is expected to improve the ability to play futsal. The resulting product is also expected to be able to assist Physical Education teachers in providing training on basic techniques of badminton service which are more varied by using the products produced. so it is expected to improve the ability to play futsal. The resulting product is also expected to be able to assist Physical Education teachers in providing training on basic techniques of badminton service which are more varied by using the products produced.

Table 1. Model

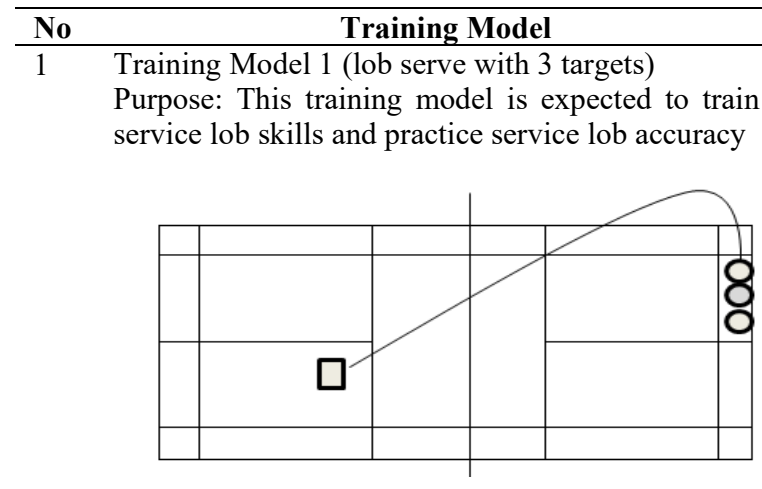

Implementation

a) Athletes are lined up to be briefed who have previously warmed up

b) The trainer explains the aims and objectives of the exercise and demonstrates them

c) Athletes perform these movements starting by standing in the area of the box or cone boundary

d) Athletes prepare to hold racket and shuttlecock

e) The athlete lobs a service and tries to put the shuttle kock into one of the 3 trash baskets that have been placed behind the opponent's field area

f) Each athlete is given the opportunity to repeat 50 times the opportunity

2 Model Exercise 2 (Lob serve with 2 targets)

Purpose: This training model is expected to train service lob skills and practice service lob accuracy

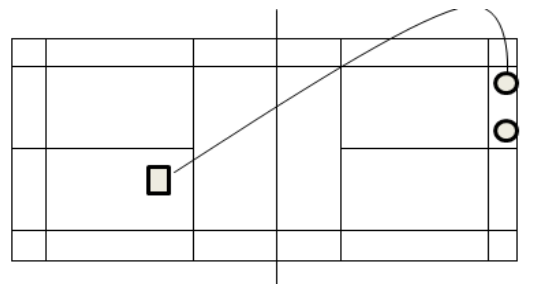

a) Athletes are lined up to be briefed who have previously warmed up

b) The trainer explains the aims and objectives of the exercise and demonstrates them

c) Athletes perform these movements starting by standing in the area of the box or cone boundary

d) Athlete holding racket and shuttlecock

e) The athlete lobs a service and tries to put the shuttle kock into one of the 2 trash baskets that have been placed behind the opponent's court area 
f) Each athlete is given the opportunity to repeat 50 times the opportunity

3 Model Exercise 3 (Lob serve with 1 target) Purpose: This training model is expected to train service lob skills and practice service lob accuracy

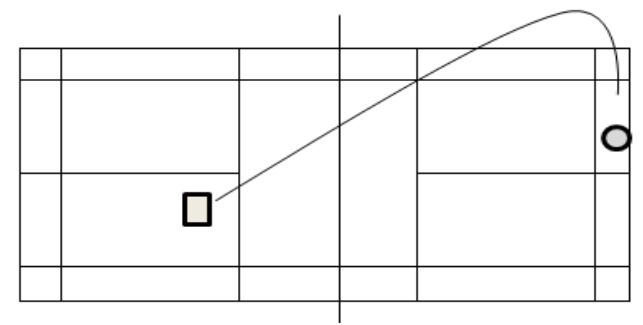

$4 \quad$ Model Exercise 4 (short serve with 3 targets)

Purpose: This training model is expected to train short serve skills and train short serve accuracy

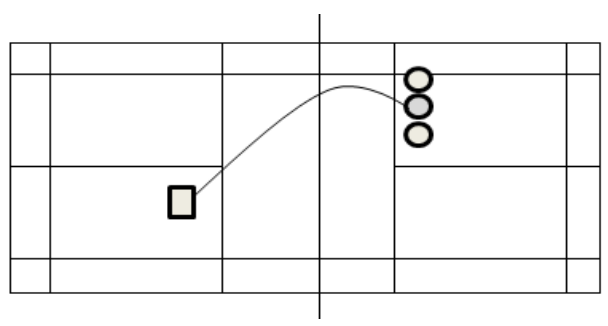

5 Model Exercise 5 (short serve with 2 targets) Purpose: This training model is expected to train short serve skills and train short serve accuracy a) Athletes are lined up to be briefed who have previously warmed up

b) The trainer explains the aims and objectives of the exercise and demonstrates them

c) Athletes perform these movements starting by standing in the area of the box or cone boundary

d) Athlete holding racket and shuttlecock

e) The athlete lobs a service and tries to put the shuttle kock into the trash basket that has been placed behind the opponent's field area

f) Each athlete is given the opportunity to repeat 50 times the opportunity

a) Athletes are lined up to be briefed who have previously warmed up

b) The trainer explains the aims and objectives of the exercise and demonstrates them

c) Athletes perform these movements starting by standing in the area of the box or cone boundary

d) Athlete holding racket and shuttlecock

e) The athlete short serves and tries to put the shuttle kock into one of the 3 trash baskets that have been placed in front of the opponent's field area

f) Each athlete is given the opportunity to repeat 50 times the opportunity.

a) Athletes are lined up to be briefed who have previously warmed up

b) The trainer explains the aims and objectives of the exercise and demonstrates them

c) Athletes perform these 
movements starting by standing in the area of the box or cone boundary

d) Athlete holding racket and shuttlecock

e) The athlete short serves and tries to put the shuttle kock into one of the 2 trash baskets that have been placed in front of the opponent's field area

f) Each athlete is given the opportunity to repeat 50 times the opportunity

6 Exercise Model 6 (short serve with 2 targets and a rope hurdle)

Purpose: This training model is expected to train short serve skills and train short service accuracy by directing the shuttle kock as close as possible to the net so that it is not easily returned by the opponent.

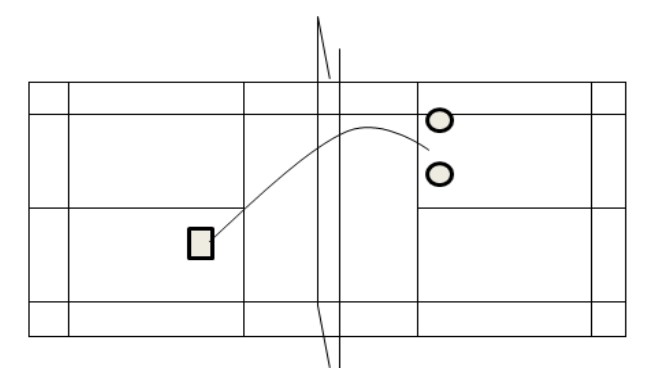

a) Athletes are lined up to be briefed who have previously warmed up

b) The trainer explains the aims and objectives of the exercise and demonstrates them

c) Athletes perform these movements starting by standing in the area of the box or cone boundary

d) Athlete holding racket and shuttlecock

e) The athlete takes a short serve and tries to insert the shuttle kock into one of the trash baskets that have been placed in front of the opponent's court area with the direction of the shuttle kock being between the net and the rope stretched out or as close as possible to the net and not exceeding the upper limit of the rope that is stretched over the net

f) Each athlete is given the opportunity to repeat 50 times the opportunity.

\subsection{Small and Large Group Trial Data Analysis}

After the product of the basic technique training model for lob and short services in badminton has been tested in small and large group trials, after testing the product will undergo changes by the experts to match the actual conditions and be effective when used during the learning / training process. When the product is tested on samples and also asks for advice from experts / experts, the product is tested by involving students.

The results of small and large group trials on the development of basic lob service techniques are as follows: 
Table 2. Average value

\begin{tabular}{lccccc}
\hline & & \multicolumn{3}{c}{ Paired Samples } & \\
& & Mean & N & Std. Deviation & Std. Mean Error \\
\hline Pair 1 & Initial Test & 23,6481 & 54 & 3.06014 & .41643 \\
& Final Test & 34,1296 & 54 & 3.70133 & .50369 \\
\hline
\end{tabular}

Table 3. Correlation Coefficient

\begin{tabular}{|c|c|c|c|c|}
\hline \multicolumn{4}{|c|}{ Paired Samples Correlations } \\
\hline Pair 1 & N & Correlation & Sig. \\
\hline $\begin{array}{c}\text { Initial Test } \\
\text { Final Test }\end{array}$ & 54 & .326 & .000 \\
\hline
\end{tabular}

Table 4. Significant Differences

\begin{tabular}{|c|c|c|c|c|c|c|c|c|}
\hline \multicolumn{9}{|c|}{ Paired Samples Test } \\
\hline & \multicolumn{5}{|c|}{ Paired Differences } & \multirow[t]{3}{*}{$\mathbf{T}$} & \multirow[t]{3}{*}{ df } & \multirow{3}{*}{$\begin{array}{c}\text { Sig. } \\
\text { (2tailed) }\end{array}$} \\
\hline & \multirow[t]{2}{*}{ Mean } & \multirow[t]{2}{*}{$\begin{array}{c}\text { Std. } \\
\text { Deviation }\end{array}$} & \multirow[t]{2}{*}{$\begin{array}{l}\text { Std. } \\
\text { Mean } \\
\text { Error }\end{array}$} & \multicolumn{2}{|c|}{$\begin{array}{l}\text { 95\% Confidence } \\
\text { Interval of the } \\
\text { Difference } \\
\end{array}$} & & & \\
\hline & & & & Lower & Upper & & & \\
\hline $\begin{array}{c}\text { Initial Test- } \\
\text { Final Test }\end{array}$ & 1,048 & 3.96 & .53900 & 11.56 & 9.40 & 19.45 & 53 & .000 \\
\hline
\end{tabular}

In the significance test for differences with SPSS 22, the results obtained t-count $=19.45$, $\mathrm{df}=53$ and $\mathrm{p}$-value $=0.00<0.05$, which means that there is a significant difference in students' badminton serve practice before and after the badminton service training model. Based on this information, it can be said that the developed badminton service training model for junior high school age beginners can effectively improve badminton service for junior high school age. The following is a comparison of the average level of the badminton service test before giving the treatment and after giving the treatment with badminton service training models with the bar chart in the following figure:

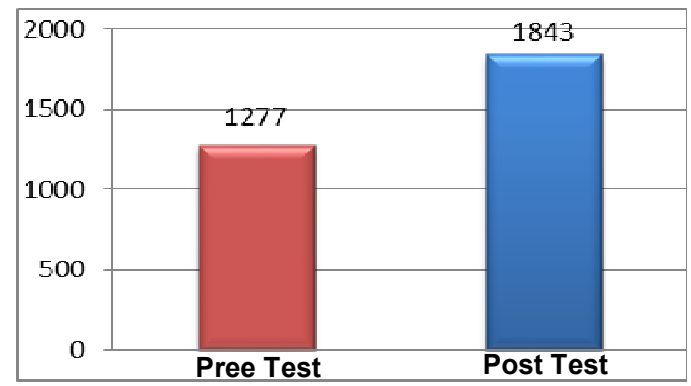

Fig.1. Bar Chart (Product Feasibility Trial)

The results of small group trials and large group trials can be concluded that the badminton service training model for junior high school age can be used in the badminton service training 
process for junior high school age and is feasible and effective to improve badminton service for athletes / students. Based on the results of the output table above, the correlation coefficient of training before and after being given a badminton service model is 0.326 with a p-value of $0.00<0.05$, so the conclusion is significant.

Based on the figures obtained in the table above, it can be concluded that the basic technical training models of lob service and short service badminton for junior high school age beginners can and are feasible and effective to be used in basic technical training of badminton service for junior high school age. There is a comparison of numbers that show that the results of the initial test and the final test have progressed, from the initial test which amounted to 1277 then given treatment in the form of basic technical training models of lob service and badminton sport short service that have been developed then the final test or post test is then held. To determine the effectiveness of the model developed and obtained data amounting to 1843 , So the basic technical training model for lob service and short service badminton is effective for developing basic badminton service training in junior high schools. Of the 6 basic technical training models consisting of 3 lob service training models and 3 short serves made above, the aim is to develop cognitive aspects, affective aspects, and psychomotor aspects. Psychomotor aspects relate to locomotor, non-locomotor and manipulative motion. According to [9] said that multilateral motion is an amalgamation of various basic movements (locomotor, non-locomotor, and manipulative motion) and the basic movement of sports skills. Seeing the shortcomings and advantages of the products made, there are inputs that researchers will convey in order to achieve the improvement of this product, while the input is as follows:

a) In this model it is necessary to adjust the movements of students who practice the basic technique models of lob service and badminton short service.

b) The use of more equipment and paying attention to comfort and safety can make children more leverage in doing movements of the basic technique model of lob service and badminton sport short service provided by the teacher / coach.

c) The characteristics and understanding of athletes / students require the teacher / trainer to provide direct practice for students to learn new movements to do.

\subsection{Product Discussion}

The basic technical model of lob service and badminton sport short service made by the researcher is a product that aims to assist teachers / coaches in delivering material to improve basic technical skills of lob service and short service for athletes / students, and as a reference for training materials. This basic service model is made based on the level of children's needs in training activities, especially the basic technique of playing badminton in badminton extracurricular sports for junior high school beginners. This product, after being reviewed regarding several weaknesses that need improvement, can be conveyed several advantages of this product, including:

a) Improve the basic technique of lob serving and short serving of badminton athletes / students.

b) This model can make athletes / students more active, and enthusiastic in practicing basic techniques of lob service and short service badminton sports.

c) Athletes / students can feel comfortable and safe in the process of badminton training at school, especially the basic techniques of lob and short service.

d) The basic technical model of lob service and badminton short serve is more effective and efficient 
e) Can assist coaches in training athletes / students in extracurricular activities in schools.

f) Contribution to science, especially physical education in schools

g) This basic technical model of lob service and badminton short serve is done systematically from easy to difficult things.

h) Athletes / students are also required to think quickly, accurately.

i) The model used is very varied which can increase the enthusiasm level of athletes / students in training.

\section{Conclusion}

Based on the data obtained, from the results of field trials and discussion of research results it can be concluded that this research and development resulted in a product of a basic technique training model for serving punches in badminton for junior high school beginners. With the development of the basic technique training model for serving strokes in this badminton game, students, coaches and teachers of physical and health education can learn and carry out the basic technique training model of serve strokes effectively and efficiently, so that students / athletes can master the theoretical and practical material of badminton. early on properly and correctly.

\section{References}

[1] J. Poole, "Learning Badminton. Bandung: Pioner Jaya, "In J. Firmansyah, Thing. 14-15, 2014.

[2] H. Tauhidman and G. Ramadan, "Development of a Balance Exercise Model for Elementary Schools," J. Sport. J. Researcher. Learning, vol. 4, no. 1, pg. 133-144, 2018.

[3] A. Suherman, Physical Education learning curriculum. UPI Sumedang Press, 2018.

[4] BJ Miller-McLemore and BJ Miller-McLemore, The Wiley-Blackwell companion to practical theology. Wiley Online Library, 2012.

[5] WR Borg and MD Gall, "Educationnal Research." London: Longman, 1983.

[6] PD Sugiyono, "Research and development methods," Res. Dev. D, vol. 2015, p. 39-41, 2015.

[7] S. Sukmadinata, "Nana. 2012, "Method. Researcher. Educator.

[8] DE Meltzer, "The relationship between mathematics preparation and conceptual learning gains in physics: A possible 'hidden variable' in diagnostic pretest scores," Am. J. Phys., vol. 70, no. 12, pg. 1259-1268, 2002.

[9] R. Lumintuarso, "The theory of sports coaching," Jakarta: Lankor, 2013. 